\title{
Redux: The James Shields Memorial Award for Twin Research
}

\author{
Irving I. Gottesman
}

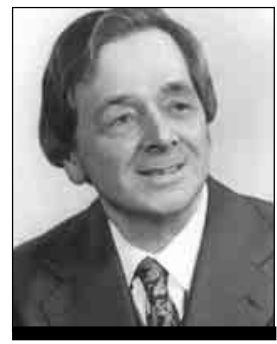

James Shields

After a hiatus of some 15 years, and following on a suggestion from Nick Martin to publicly reconstruct the roots of modern twin research strategies for a contemporary audience, the James Shields Memorial Award for Twin Research was happily restored. The fact that our conversation took place during a meeting _ "The Future of Behavioural Genetics in a Post-Genomic World" — we attended in Hinxton at the Sanger Centre under the auspices of The Wellcome Trust, guided by Robert Plomin, John DeFries, Peter McGuffin, and Ian Craig, made it a timely suggestion. It is inefficient to construe the future without an accurate appreciation of the past.

The Award was initiated after the untimely death of Shields in 1978, shortly before his 60th birthday, at the peak of a brilliant career as a scholar and world-renowned twin researcher. I invited Len Heston, David Fulker, and Dick Rose to join me in establishing the memorial; the award was thereafter to be made at the annual meetings of the Behavior Genetics Association. It will now be administered by Greg Carey (USA), Chair, Nick Martin (Australia), Hill Goldsmith (USA), and Irv Gottesman (USA, ex officio), and it will be awarded at the international congresses of the International Society for Twin Studies. The list of awardees up through 1986 is comprised of the following eminent (then young) twin researchers: Aksel Bertelsen (Denmark, 1985), Ronald Wilson (USA, 1980), Peter Propping (Germany, 1983), Lindon Eaves (UK/USA, 1981), Nick Martin (Australia, 1986), Dick Rose (USA, 1982), and Hill Goldsmith (USA, 1984). Continuing the tradition, and the recognition of excellence, after the redux we have (see below) Jaakko Kaprio (Finland, 2001).

\section{The Life of James Shields}

In brief (cf. In Memoriam published Behavior Genetics, 9, 1-16, 1979 and Acta Geneticae Medicae et Gemellologiae, 28, 83-90, 1979 by I.I. Gottesman), James Shields rose above traumatic life events to achieve his greatness as an intellectual and as a scientist. He was captured in combat near Dunkirk in 1940 at age 22, serving as a decorated gunner in the Royal Artillery, and spent five years in a prisoner-of-war Stalag. Fate struck again in 1954, during his field work on the then largest ever study of identical twins reared apart, when he contracted polio and survived a bout in an iron lung. He had commenced work in 1947 as psychiatric social worker and research associate to Eliot Slater [1904 - 1983] at the Institute of Psychiatry in London, co-authoring the 1953 monograph on psychotic and neurotic illnesses in twins that Slater had commenced before the start of World War II. Shields' own monograph on monozygotic twins brought up apart and brought up together was published in 1962, rivaling and surpassing the infamous reports by Sir Cyril Burt. It was also in 1962 that our lives began to entwine, at first by post, and the next year in person, at which time we were paired by Slater to study the twins with possible schizophrenia diagnoses in the Maudsley Twin Register that had been initiated by Slater and Shields in 1948 and at that time contained some 590 probands from consecutive admissions to the Maudsley-Royal Bethlem Hospitals. He was a prolific author and mentor to a world-wide group of twin investigators. Among his awards were the Hofheimer Prize (1973) from the American Psychiatric Association, and a rare Honorary Degree of Doctor of Medicine (1975) from the University of Zurich, following in the footsteps of Miss Anna Freud, also without a higher degree. We worked closely in every respect implied by a meeting of minds, until his death. Jerry Shields was indeed a man for all seasons, an exemplar to us all.

\section{Jaakko Kaprio: Acceptance Speech July 7, 2001}

It is a great honour for me to receive the James Shields award. He is recognized for his work in psychiatric genetics here at the Institute of Psychiatry in London, but especially for his landmark study of monozygotic twins

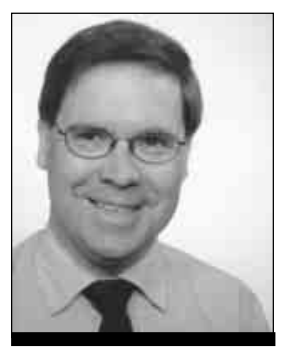

Jaakko Kaprio reared apart and reared together. I would like to thank the International Society for Twin Studies, its Board of Officers and the award committee for considering me worthy of this distinguished prize. I believe I have received it in recognition not only of my personal merits, but also as a representative of the researchers who have worked with me on the Finnish Twin Cohort study as well as on behalf of those who have worked in behavioural genetics and twin studies in Finland. In the 1930s a Finnish psychologist Arvo Lehtovaara carried out the first large twin study in Helsinki on children examining a wide range of traits. Some 30 years later, alcohol-related behaviours were studied among male twin pairs born in 1920-1929 
by a group of researchers at and associated with the State Alcohol monopoly research institute. Their work, notably reported in the monograph by Partanen, Markkanen and Bruun, was the first to demonstrate the importance of biological and inherited factors in alcohol use, abuse and related behaviours in a large-scale population -based twin study. Professor Irma Moilanen from Oulu has continued this fine tradition of twin studies in her studies over more than two decades in child and adolescent psychiatry.

I have been involved in the creation and followup of several large-scale cohort studies of twins since 1976. The older Finnish Twin Cohort of twin pairs then aged 18 and over was created in 1974 from population register data; baseline information collected by a broad-based socio-medical questionnaire in 1975 on nearly 14000 twin pairs. Follow-up questionnaire surveys were carried out in 1981 and 1990, and numerous selected samples of twins have participated in more intensive medical and behavioural studies. Thus, follow-up of this cohort has now continued for the quarter of a century, with the publication of numerous research reports on medical, genetic and behavioural questions. Though the original purpose of the study was to examine the relationship between smoking and medical outcomes, the broad data collection, large sample size and long follow-up have permitted many other interesting questions to be addressed. We now have several ongoing studies in psychiatric genetics, the field of James Shields. While many people have been involved in the Finnish Twin Cohort study, I would like to thank in particular professor Markku Koskenvuo for many years of close and fruitful collaboration.

In the early 1990s the Finnish twin cohort studies were expanded to focus on health-related behaviors and their development in adolescence. The FinnTwin 16 and FinnTwin 12 studies are intensive, longitudinal studies of two five-year birth cohorts (1975-1979 \& 1983-1987) of twins initially aged 16 and 12 respectively, their parents and sibs. They are now in their waves of data collection. While the health of the twins is of interest, as seen in our reports on asthma and atopy, the main thrust of the studies is to examine the development of behaviors such as alcohol use, smoking and physical inactivity, as well as the role of genetics and environment in that development. Professor Richard Rose, Indiana University, and Professor Lea Pulkkinen, University of Jyvaskyla, have been key collaborators. These two studies are the basis for many presentations at this congress.

I would also like to thank everyone else with whom I have had the pleasure of working over the years, our research staff and above all, the twins and their families in Finland.

Finally, I would like to thank all members of the Society for their support and cooperation during the two terms that I have served as Secretary-General of ISTS, in particular the two boards and presidents Robert Derom and Elizabeth Bryan. 